\title{
Cough response to citric acid aerosol in occasional smokers
}

\author{
J C POUNSFORD, K B SAUNDERS
}

\begin{abstract}
Twenty two normal women volunteers underwent a standard cough provocation test by inhaling solutions of citric acid of progressively increasing concentration. Eight were non-smokers, eight moderate smokers, and six occasional smokers. All the non-smokers and moderate smokers coughed. Moderate smokers tended to cough more than non-smokers, but not significantly so. None of the occasional smokers coughed at all $(p<0.001)$.

Possibly the ability to smoke occasionally with enjoyment is a marker for a diminished cough reflex.
\end{abstract}

\section{Introduction}

Inhalation of citric acid induces cough in man. ${ }^{1}$ We have reported that the cough response elicited is self limiting and reproducible but has a diurnal variation and shows adaptation when repeated after one hour. ${ }^{2}$ In our study two subjects did not cough at all at any citric acid concentration. Further questioning disclosed that they both smoked cigarettes occasionally (about one a week). With difficulty we found four more occasional smokers. All six were women aged between 20 and 30 . We compared the cough response of this group with that of eight regular smokers and eight non-smokers, also women and in the same age range.

\section{Subjects and methods}

All 22 normal female subjects were members of the hospital staff who gave their informed consent. The subjects were aged between 20 and 30 , and none gave a history of atopy or an upper respiratory tract infection in the two months before the study. Eight were non-smokers (mean age 23.2 years), eight smoked between 10 and 20 cigarettes a day (mean age $27 \cdot 2$ years), and six were occasional smokers and smoked between one and five cigarettes a week (mean age 23.3 years). We did not ask about the types of cigarettes smoked, but the subjects' smoking habit had been unchanged for at least three years. No study was performed within three hours of any subject having smoked a cigarette. The time of day at which the study was conducted was matched for each of the three groups.

None of the subjects was aware of the hypothesis recounted in the discussion nor of our preliminary finding of a diminished cough response in the two occasional smokers whom we first encountered.

The principle of the method we used (described elsewhere ${ }^{2}$ ) is to record coughs by a mercury strain gauge around the neck in response to successive single inhalations of increasing concentrations of nebulised citric acid. The concentration at which coughing first occurs in a subject is the "cough threshold."

\section{Results}

Habitual smokers and non-smokers all coughed at some concentration of citric acid. Surprisingly, none of the occasional smokers coughed at all $(\mathbf{p}<0.001 ;$ Fisher's exact test, two sided). There was a tendency for smokers to cough more than non-smokers (table), but this was not significant ( $>>0.05$; Wilcoxon signed rank test).

The mean cough threshold in the smokers (13.3 (SD 2.2)\%) was lower than that in the non-smokers $(18 \cdot 8(2 \cdot 0) \%)$ but not significantly so.

\footnotetext{
Department of Medicine I, St George's Hospital Medical School, London SW17 ORE

J C POUNSFORD, MB, BS, research fellow

K B SAUNDERS, MD, FRCP, professor of medicine

Correspondence to: Dr J C Pounsford, Frenchay Hospital, Bristol BS16 1LE.
}

Coughing recorded in infrequent smokers $(n=6)$, smokers $(n=8)$, and non-smokers $(n=8)^{\star}$

\begin{tabular}{lrrrr}
\hline & \multicolumn{5}{c}{ Citric acid concentration (\%) } \\
\cline { 2 - 5 } & 4 & 8 & 16 & 32 \\
\hline Total No of coughs: & & & & \\
$\quad$ Infrequent smokers & 0 & 0 & 0 & 0 \\
$\quad$ Smokers & 3 & 7 & 18 & 36 \\
$\quad$ Non-smokers & 4 & 6 & 14 & 20 \\
\% Of subjects who coughed: & 0 & 0 & 0 & 0 \\
$\quad$ Infrequent smokers & 25 & 25 & 63 & 100 \\
Smokers & 13 & 13 & 50 & 75 \\
$\quad$ Non-smokers & & & & \\
\end{tabular}

^Non-smokers all coughed at some concentration, but two did not cough at the $32 \%$ concentraton of citric acid.

\section{Discussion}

Smoking a first cigarette is normally an unpleasant experience, since it causes coughing and often nausea. If the subject persists in smoking these symptoms progressively diminish and then disappear, leaving more pleasurable effects. Occasional smokers are uncommon (we had difficulty in finding enough to study). We postulate that they may have naturally diminished cough responses which permit them to smoke infrequently without the unpleasant symptoms which affect the non-habituated smoker. This is not to imply that subjects with diminished cough response preferentially become infrequent smokers but that they have the ability to do so. Clearly, they may become non-smokers or regular smokers if they wish. It would be interesting, but ethically out of the question, to see what would happen to their cough response if they increased their cigarette consumption to moderate levels. When selecting subjects for trials of antitussive drugs it will clearly be important to separate occasional smokers from non-smokers or regular smokers.

We included regular smokers and non-smokers as controls of appropriate sex in appropriate numbers. Our results (table) show that a much larger study would be required to detect any difference in cough response between these two groups.

\section{References}

1 Bickerman HA, Barach NC. The experimental production of cough in human subjects induced by citric acid aerosol. Am f Med $S_{c i}$ 1956;228:156-63.

2 Pounsford JC, Saunders KB. Diurnal variation and adaptation of the cough response to citric acid in normal subjects. Thorax 1985;40:657-61.

(Accepted 7 October 1986)

\section{YEARS AGO}

A correspondent calls attention to the practice, sanctioned by the clergy, of allowing the coffin to be brought into the church during the early part of the funeral service which takes place inside the church. In some parts of the year, this is not only offensive but even dangerous to those who sit by the decaying human tabernacle, and no possible good can result from it. The idea of bringing the corpse inside the church is, our correspondent points out, a superstition which came in about the fourth century, when the apostacy from the early faith began. The coffin, as is pointed out, might as easily be left in the porch. This is a matter to which attention may well be directed, and members of the profession would do well to endeavour to influence the clergy in favour of some change in respect to this ancient but unsanitary custom. (British Medical Fournal 1886;ii:935.) 